\title{
Can Personality Traits Predict Depression during the COVID-19 Pandemic?
}

\section{Gabriel Nudelman $^{1}$ (D) Shanmukh Vasant Kamble ${ }^{2} \cdot$ Kathleen Otto $^{3}$}

Accepted: 25 May 2021 / Published online: 1 June 2021

(c) The Author(s), under exclusive licence to Springer Science+Business Media, LLC, part of Springer Nature 2021

\begin{abstract}
The emotional costs of the COVID-19 pandemic have raised concerns among clinicians and scholars. The goal of the current study was to test whether or not neuroticism, conscientiousness, and personal belief in a just world are associated with depression during the COVID-19 pandemic. Moreover, the contribution of neuroticism and conscientiousness was assessed over and above demographic variables and COVID-19 perceptions, and the unique contribution of personal belief in a just world was evaluated beyond all the other study variables. Samples were collected in three different countries-Israel $(N=917)$, Germany $(N=213)$, and India $(N=160)$. Online self-report questionnaires were utilized to measure age, gender, COVID-19 perceptions (probability, severity, and self-efficacy), neuroticism, conscientiousness, personal belief in a just world, and depression. The findings indicated that, across the three countries, neuroticism was positively associated with depression (correlations ranging from .24 to .44), and conscientiousness and personal belief in a just world were negatively associated with depression (correlations ranging from -.31 to -.21 , and from -.35 to -.23 , respectively). Moreover, neuroticism and conscientiousness explained unique variance over and above demographic variables and COVID-19 perceptions (except conscientiousness in India), and the effect of personal belief in a just world on depression was significant beyond the effects of all other study variables. These findings support the role of personality in explaining depression regardless of situational characteristics and stress the role of just world beliefs as protective factors against negative emotions.
\end{abstract}

Keywords Depression · COVID-19 · Belief in a just world · Neuroticism · Conscientiousness

Gabriel Nudelman

gabrielnu@mta.ac.il

1 School of Behavioral Sciences, The Academic College of Tel Aviv-Yaffo, Rabenu Yeruham St., P.O.B 8401, 6818211 Yaffo, Israel

2 Department of Psychology, Karnatak University, Dharwad, India

3 Faculty of Psychology, Philipps University, Marburg, Germany 


\section{Introduction}

The world is currently facing the COVID-19 pandemic, caused by the SARSCoV-2 virus (World Health Organization, 2020a). Other than infecting millions worldwide, it has spread fear and changed the way people conduct themselves in daily life. Different countries enforced lockdowns to mitigate the spread of COVID-19, and the public was asked to follow guidelines such as staying at home and social distancing (Centers for Disease Control \& Prevention, 2020; World Health Organization, 2021). Such drastic measures and the global nature of the threat have led to increased fear and worry (Ahorsu et al., 2020).

According to several theories, the fear motivating individuals to follow instructions is related to a number of central factors, such as perceptions of susceptibility to the disease, severity of the disease, and self-efficacy to protect oneself (Maddux \& Rogers, 1983; Rosenstock, 1974; Ruiter et al., 2014; Witte, 1992). In other words, greater perceptions of susceptibility or severity of COVID-19 may cause greater fear, which authorities hope would be translated to a greater willingness to follow health guidelines. However, both the fear aroused and some of the behavioral recommendations (e.g., isolation) can have detrimental effects. Consequently, there is a growing concern regarding the emotional costs of the pandemic and its disruption of daily life, such as experiencing depression and anxiety (Hyland et al., 2020). The purpose of the current research was to assess whether or not general personality traits were able to predict depression, in light of the concerns and findings regarding negative emotional states related to COVID-19. Specifically, we examined the associations between depression and neuroticism, conscientiousness, and personal belief in a just world.

The Big Five Model is considered a general taxonomy of personality traits that is based on the lexical hypothesis and includes five general dimensions: neuroticism, extraversion, agreeableness, conscientiousness, and openness to experience (Goldberg, 1992; John \& Srivastava, 1999). This structure of personality was found stable across cultures and time (Schmitt et al., 2007; Wagner et al., 2019).

The Big Five were also found to predict depression, and various models have been proposed to explain this association, such as the vulnerability model that suggests personality can predict who will develop psychopathology among previously unaffected individuals (Clark, 2005). This model, also referred to as the predisposition model, was proposed to explain psychological co-morbidity, i.e., that the presence of an existing disorder increases the probability of developing an additional disorder. It postulates that an individual with a specific subset of maladaptive personality traits may be predisposed to particular disorders, such as depression, by evoking certain responses that facilitate the development of such disorders (Krueger \& Tackett, 2003). Following mixed results regarding the relationships between the five personality traits and depression, a meta-analysis concluded that only higher neuroticism and lower conscientiousness were significantly and robustly associated with depression (Kotov et al., 2010).

Neuroticism, sometimes inversely labeled emotional stability, relates to a person being anxious and easily upset (John \& Srivastava, 1999). The link between 
depression and neuroticism can be explained by the vulnerability model, since neuroticism is strongly associated with high levels of negative affect and low levels of positive affect (Watson et al., 1999), which may lead to depression (Clark \& Watson, 1991). Conscientiousness, which refers to a person being dependable, orderly, an thorough (John \& Srivastava, 1999), consistently yielded strong negative effects on depression and other psychopathologies (Malouff et al., 2005). This corresponds with findings regarding low conscientiousness as the strongest personality predictor of poor engagement in health behaviors and of mortality (Bogg \& Roberts, 2004; Kern \& Friedman, 2008; Nudelman \& Ivanova, 2018). One explanation for this association relates to the vulnerability model, suggesting that individuals low in conscientiousness are predisposed to academic difficulties, job loss, and other failures, which can contribute to psychopathology (Klein et al., 2011). Consequently, the first goal of the current study was to investigate the pattern of associations between depression during the COVID-19 pandemicwhich many people might experience due to situational factors-and neuroticism and conscientiousness.

Another personality trait with implications for mental health is the belief in a just world, which maintains that people get what they deserve (Lerner, 1980). This belief is thought of as a stable personality trait (Dalbert, 2001), since it serves as an important adaptive function that provides psychological protection from unjustified consequences (Lerner \& Miller, 1978). The literature distinguishes between two forms of the belief in a just world (Dalbert, 1999): personal (concerning the self) and general (concerning others or everyone). Personal belief in a just world, and not the general belief, was found related to subjective well-being and life satisfaction (Correia \& Dalbert, 2007; Dalbert, 1999; Lipkus et al., 1996; Sutton \& Douglas, 2005; Sutton et al., 2017). This was attributed to the ability of personal belief in a just world to act as an effective coping mechanism, decreasing stress and other negative emotions (Bartholomaeus \& Strelan, 2019; Dalbert, 2001; Furnham, 2003).

Moreover, higher personal belief in a just world was associated with lower levels of depression in various contexts (Kamble \& Dalbert, 2012; Otto et al., 2006). These findings can be interpreted using the vulnerability model, wherein a central worldview that is related to various life domains (Koltko-Rivera, 2004) forms a predisposition that translates into maladaptive responses. For example, a weak belief in a just world may lead to lower internal locus of control (Nudelman \& Otto, 2021), which in turn may translate into perceived helplessness, a well-known antecedent of depression (Pryce et al., 2011). Therefore, consistent with theoretical considerations and previous findings, we expected higher personal belief in a just world to be related to lower depression also during the COVID-19 pandemic.

\section{The Current Study}

Our goal was to test the effect of neuroticism, conscientiousness, and personal belief in a just world on depression during the COVID-19 pandemic. This was achieved, firstly, by examining whether or not the associations replicate during the pandemic. Since it may take some time for depressive symptoms to develop, 
we collected data about two months after the initial lockdown. This period included limitations to daily life and the people were strongly advised to stay at home, allowing enough time to pass to cause emotional strain that may result in depression (Diagnostic and Statistical Manual of Mental Disorders, 5th ed.; American Psychiatric Association, 2013, p. 160).

Secondly, to further examine the aforementioned effects, we assessed whether or not they could explain depression beyond other relevant factors, namely age, gender, and COVID-19-related perceptions. While the Big Five personality traits are known for their stability (Cobb-Clark \& Schurer, 2012), their associations with depression might be affected by unique circumstances wherein adverse situational factors, such as lockdowns due to a global pandemic, become determinants of depression (Canet-Juric et al., 2020). Consequently, we examined the effects of neuroticism and conscientiousness on depression over and above demographic variables and COVID-19 perceptions, which may be strong determinants of negative emotional states during the pandemic and overlap with variability explained by personality. Moreover, considering the associations of personal belief in a just world with neuroticism and conscientiousness (Nudelman, 2013; Nudelman \& Otto, 2021), we assessed the effect of personal belief in a just world on depression after controlling for the contribution of all other study variables, to test for its unique protective properties, unrelated to other major personality traits, during the threatening COVID-19 pandemic.

Finally, in order to examine whether or not the findings were consistent across samples and cultures, we tested our hypotheses across three samples from three countries-Israel, Germany, and India-that differ on various dimensions. In terms of culture, the power distance is largest in India, while it is smallest in Israel. However, Israel is closer to India on the cultural dimension of collectivism compared with Germany (Hofstede et al., 2010; Purohit \& Simmers, 2006). Moreover, trust in government was higher in India than in an average of the OECD countries, and higher in Germany compared with Israel (OECD, 2013, 2021), and Germany and Israel are considered high income countries, while India is part of the lower-middle-income group (The World Bank, 2020). These differences might influence the reactions during COVID-19, such as individuals in collectivistic cultures-compared with individualistic cultures-suffering more from social isolation.

Therefore, this study was expected to contribute to the literature by examining the replicability of previously found relationships between personality traits and depression during the COVID-19 pandemic, evaluating these effects beyond those of demographic and situational characteristics, and assessing them across three nations. In sum, our hypotheses were as follows:

Hypothesis 1 Higher neuroticism and lower conscientiousness would be related to higher depression.

Hypothesis 2 Higher personal belief in a just world would be related to lower depression.

Hypothesis 3 Neuroticism and conscientiousness would explain variance in depression over and above demographic variables and COVID-19 perceptions. 
Hypothesis 4 Personal belief in a just world would explain variance in depression over and above demographic variables, COVID-19 perceptions, and neuroticism and conscientiousness.

\section{Methods}

\section{Procedure}

The study was part of a larger project that included additional measures and that was approved by the Institutional Review Board of the first author's Academic Institute. It was conducted online in May-June 2020 across all three countries, using the online platforms Qualtrics (in Israel and India) and SocSci (in Germany). The study was presented as assessing perceptions, beliefs, and behaviors in general and related to the novel coronavirus (COVID-19). After assuring participants of anonymity and that they could stop at any time, they were asked for their consent and for confirmation of being above 18 years old. Then, participants completed the personal belief in a just world, neuroticism, and conscientiousness measures in random order, followed by the depression scale and COVID-19 perceptions and beliefs. The items within each measure were also randomized, and demographic variables were collected at the end of the survey.

A representative sample was collected in Israel by a survey company. In Germany and India, convenience samples were collected using personal contacts, research assistants, and by distributing the link to the survey via universities' students and staff listservs. All participants received compensation in Israel, and raffles of monetary vouchers were conducted among participants in Germany and India.

\section{Participants}

Samples from three countries were requested to complete online questionnaires. Participants in each sample were included if they did not demonstrate careless responding (Meade \& Craig, 2012) by answering two attention check questions correctly (e.g., "please mark the answer "completely agree") and indicating at the end of the study that they had answered the questions seriously.

\section{Israel Sample}

The number of participants who completed the survey was 1,036, of which 917 remained after exclusion due to careless responding (445 men and 472 women). Age ranged between 18 and 86, with a mean of $39.45(\mathrm{SD}=14.62)$, and two participants reported having confirmed COVID-19. 


\section{Germany Sample}

The number of participants who completed the survey was 243, of which 222 remained after exclusion due to careless responding. However, 6 participants did not indicate their gender and 3 did not indicate the perceived probability or severity of COVID-19, leaving 213 for the final analyses (59 men and 154 women). Age ranged between 18 and 71, with a mean of 29.66 ( $\mathrm{SD}=11.68$ ), and no confirmed COVID19 cases.

\section{India Sample}

The number of participants who completed the survey was 326, of which 160 remained after exclusion due to careless responding (48 men and 112 women). Age ranged between 18 and 52, with a mean of $27.98(\mathrm{SD}=6.95)$, and no confirmed COVID-19 cases.

\section{Measures}

Internal consistencies (Cronbach's $\alpha$ or correlation) are presented in Table 1.

\section{Demographic Variables}

Information regarding age (in years) and gender (male or female) was collected, as well as whether or not a participant had a confirmed COVID-19 diagnosis.

\section{COVID-19 Perceptions}

Participants were told that they will be presented with questions related to the novel coronavirus (COVID-19). Three items from the COVID-19 Survey Tool and Guidance (World Health Organization, 2020b) were selected to represent three aspects: "What is your probability of getting infected with the novel coronavirus?" represented probability (answers ranged from $1=$ extremely unlikely to $7=$ extremely likely); "How severe would contracting the novel coronavirus be for you?" represented severity (answers ranged from $1=$ not severe to $7=$ very severe); and "I know how to protect myself from coronavirus" represented self-efficacy (answers ranged from $1=$ not at all to $7=$ very much so).

\section{Neuroticism and Conscientiousness}

Measured using the BFI-10 (Rammstedt \& John, 2007), participants were asked to indicate how well sentences describe their personality on a scale of $1=$ completely disagree to $7=$ completely agree. There were two items for neuroticism (e.g., "I see myself as someone who gets nervous easily") and two for conscientiousness (e.g., "I see myself as someone who does a thorough job"). An average was calculated for each pair of items, with higher scores representing higher levels of the construct. 


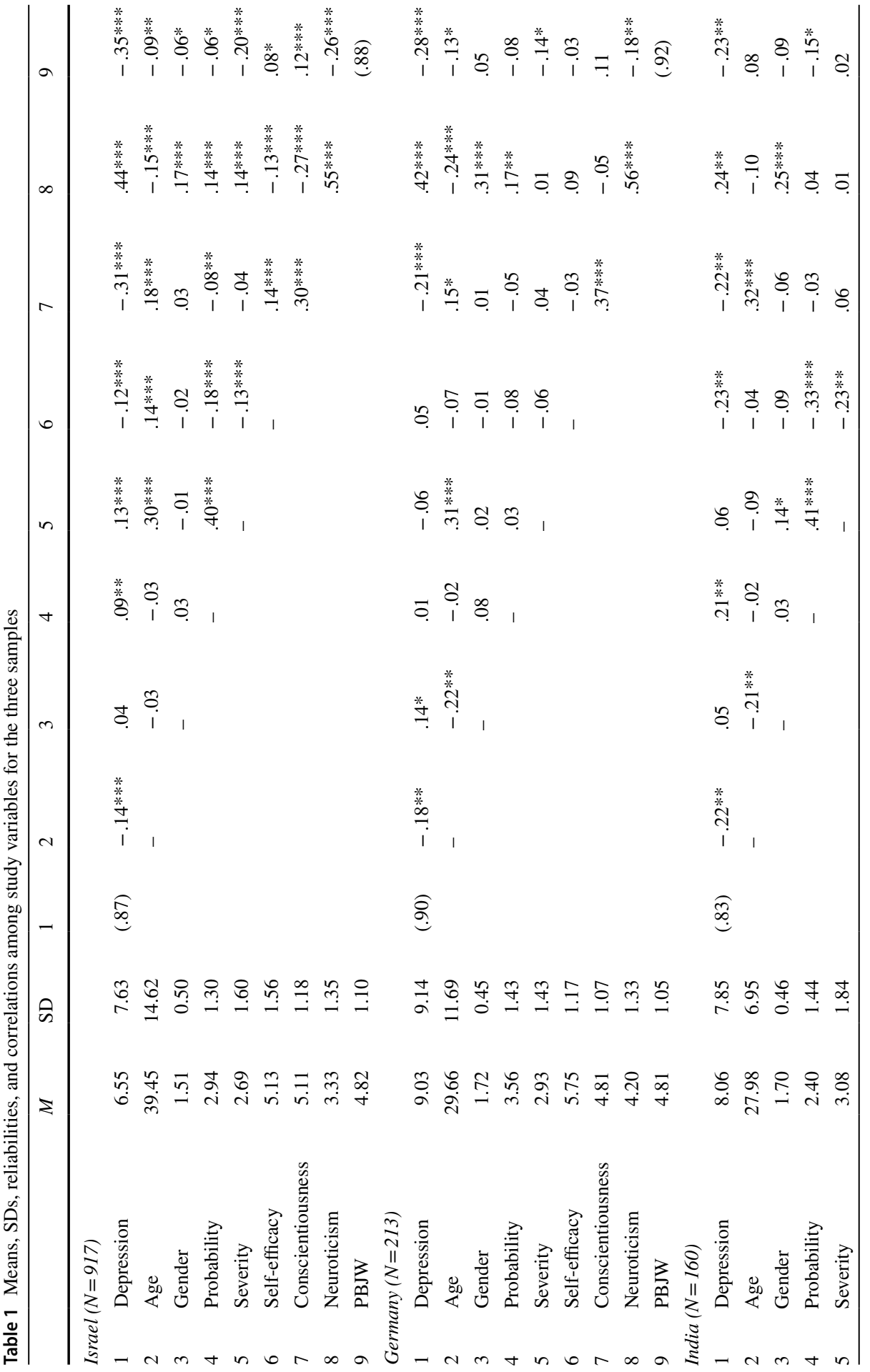




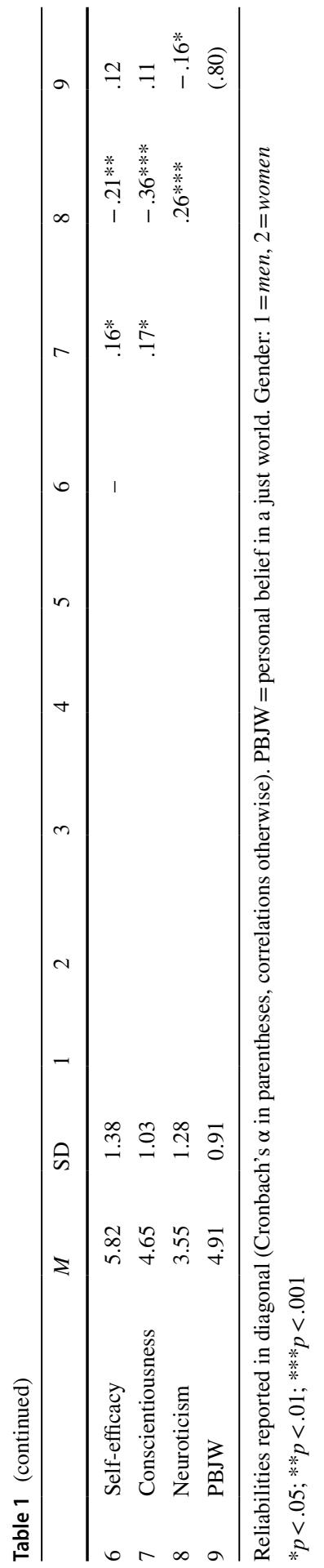




\section{Personal Belief in a Just World}

Measured using the personal belief in a just world scale (Dalbert, 1999), participants were asked to indicate the extent to which they agree or disagree with each one of seven statements (e.g., "I believe that, by and large, I deserve what happens to me"). An average was calculated across items, with higher numbers representing a stronger belief.

\section{Depression}

Measured using the DASS-21 depression sub-scale (Lovibond \& Lovibond, 1995). Participants were asked to indicate the degree to which each one of seven items assessing depression (e.g., "I felt downhearted and blue") applied to them over the past week, on a scale ranging from $0=$ did not apply to me at all to $3=$ applied to me very much or most of the time. A sum was calculated across items and multiplied by two, resulting in a single depression score for each participant, with higher scores representing higher depression (Lovibond \& Lovibond, 1995).

\section{Statistical Analysis}

The surveys administered in Israel and India applied a force response option, resulting in no missing data. The German survey did not include this option, but this resulted in only $0.3 \%$ unanswered items out of the entire data. This corresponds to missing data mostly for a single item for a few participants. Consequently, in case of average calculations, the relevant measure was calculated without the missing item; in case of sum calculations, the average of the other items of the participant replaced the score of the missing item; and in case of single items, the participant was excluded from the analysis, due to the regression calculations described in what follows, which necessitate complete data.

Pearson correlations were calculated for all the variables in the study, which provided answers for the hypotheses regarding bivariate associations. Hierarchical linear regression analyses were utilized for testing effects on depression over and above other effects. Thus, demographic variables were entered in the first step, COVID-19 perceptions in the second step, neuroticism and conscientiousness in the third step, and personal belief in a just world was entered in the fourth step. All analyses were conducted in an identical manner for the three samples.

\section{Results}

Means, standard deviations and correlations between study variables are presented in Table 1. Older age was associated with less depression across the three samples, while the correlation between depression and gender was inconsistent. Hypothesis 1 was confirmed: Depression was significantly and positively correlated with 


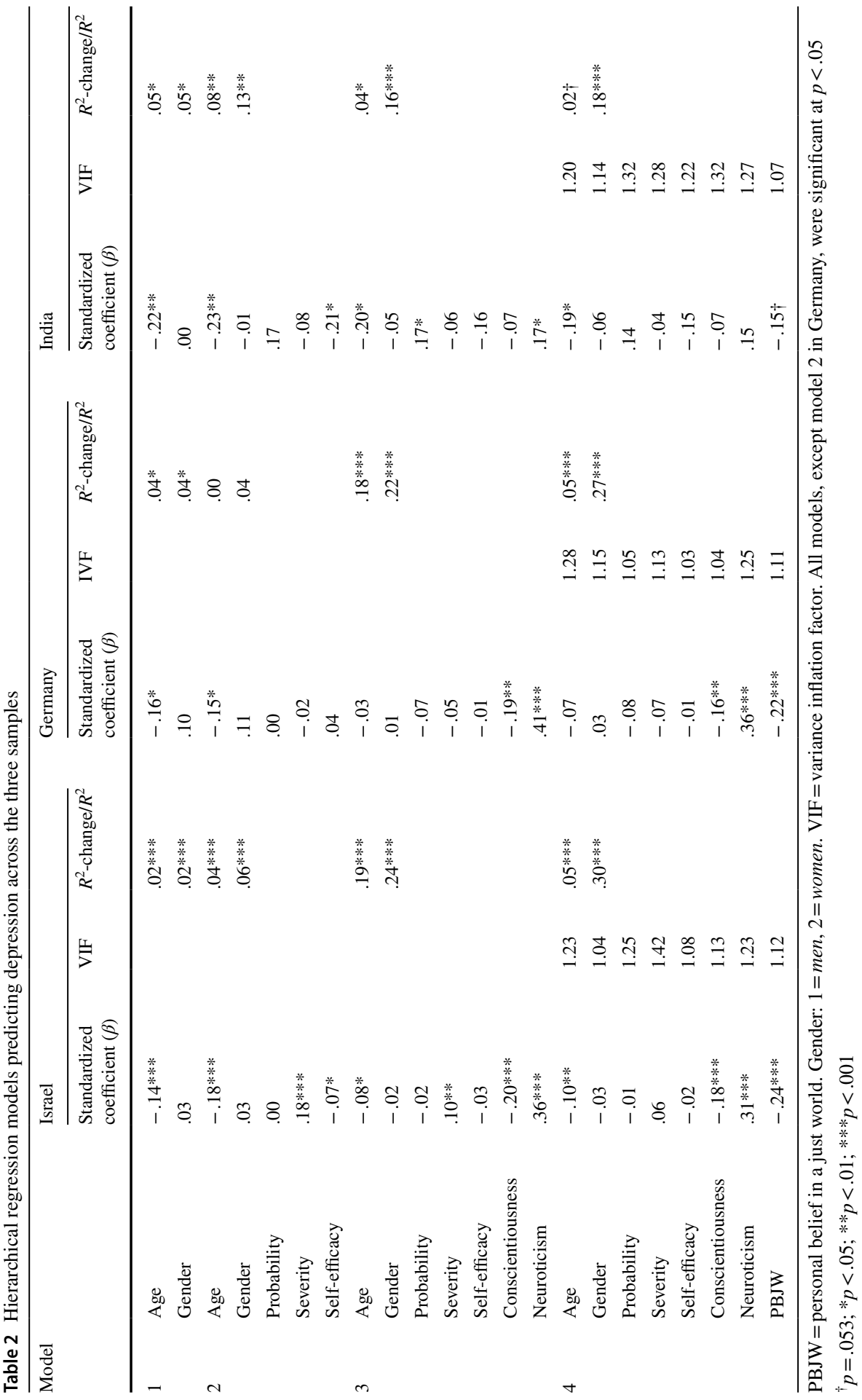


neuroticism and negatively with conscientiousness across the three countries. The correlations with neuroticism ranged from 0.24 to 0.44 , and with conscientiousness from -0.31 to -0.21 . In line with hypothesis 2 , significant negative correlations were found between personal belief in a just world and depression across the three samples, ranging from -0.35 to -0.23 . The strongest correlation was in the sample from Israel, followed by Germany, and weakest in India.

Hypothesis 3 was mostly supported: Neuroticism and conscientiousness (step 3) explained significant variance over and above demographic variables and COVID-19 perceptions across all three countries (Table 2). However, while both personality traits were significant in the samples from Israel and Germany, only neuroticism was a significant predictor of depression in the regression equation in the sample from India. This is also reflected in the largest change in explained variance demonstrated after adding neuroticism and conscientiousness in the samples from Israel and Germany, but not in the sample from India (Table 2).

Consistent with Hypothesis 4, personal belief in a just world was a significant predictor of depression over and above demographic variables, COVID-19 perceptions, and conscientiousness and neuroticism, in the sample from Israel and Germany, and marginally significant in the sample from India (Table 2).

\section{Discussion}

The purpose of the current study was to examine the effect of certain personality traits on depression during the COVID-19 pandemic. As expected, depression was negatively associated with personal belief in a just world and conscientiousness, and positively with neuroticism, across three samples from three countries. Moreover, consistent with our hypotheses, the patterns of the bivariate associations generally continued over and above demographic variables and COVID-19 perceptions: neuroticism and conscientiousness explained changes in depression, and personal belief in a just world explained changes in depression above all other study variables.

Out of the Big Five, neuroticism and conscientiousness were found to consistently explain depression (Kotov et al., 2010). This pattern was also found in the current study, across three countries during the COVID-19 pandemic. Moreover, since the associations were lower than the average associations found in a previous meta-analysis, but within an $80 \%$ credibility interval (Kotov et al., 2010), the links between depression and neuroticism and conscientiousness appear to remain stable during the pandemic. Neuroticism also emerged as a strong predictor of depression beyond COVID-19 perceptions and demographic variables. Higher neuroticism, symbolizing less emotional stability, was associated with higher levels of depression, which is logical since both constructs are strongly related to higher negative mood and anxiety (Lerman et al., 2015; Paulus et al., 2016). Conscientiousness was a significant predictor in the samples from Israel and Germany, although less prominent than neuroticism in predicting depression, and did not reach significance in the sample from India when COVID-19 perceptions and demographic variables were included in the regression equation (although the coefficient was in the expected direction). This might be due to its medium-effect-sized correlation 
with age, suggesting that, at least in India, older people are both more conscientious and less depressed. Nevertheless, since individuals with higher conscientiousness also engage more in health behaviors, and achieve higher academic success and job performance (Bogg \& Roberts, 2004; Dudley et al., 2006; O'Connor \& Paunonen, 2007), all linked to better health and well-being (Bücker et al., 2018; Cropanzano \& Wright, 1999; Nudelman \& Ivanova, 2018), it is likely that the negative association between conscientiousness and depression has unique characteristics beyond those of demographic or other factors.

The expected link between depression and personal belief in a just world was also significant. This relationship replicates past findings depicting an association between stronger personal belief in a just world and higher well-being (Donat et al., 2016; Hafer et al., 2020) and lower depression (Kamble \& Dalbert, 2012; Otto et al., 2006). Most investigations of the link between personality and depression do not include just world measures (for a review, see Klein et al., 2011), and previously found associations between personal belief in a just world and neuroticism and conscientiousness (Nudelman, 2013; Nudelman \& Otto, 2021) might imply that the effect of personal belief in a just world on depression is a byproduct of an overlap between these personality constructs. However, our findings revealed that personal belief in a just world explained depression over and above not only demographic variables and COVID-19 perceptions, but also neuroticism and conscientiousness. This attests to the unique role of personal justice beliefs in providing protection from negative mood (Dalbert, 2002; Nudelman \& Nadler, 2017), in line with the vulnerability model. It is also consistent with the representation of the personal belief in a just world as a resource that maintains well-being in everyday life, which is achieved by providing a sense of meaning and control that leads people to act in a just manner-since they expect their behaviors to result in just consequences, i.e., that they will get what they deserve (Dalbert, 2001). In the context of COVID-19, this might manifest itself as a belief that one will not get infected or not become severely ill if infected, or that a person is protected as long as s/he does not do anything to bring about the disease. Thus, future studies should examine which personal belief in a just world functions are more dominant in explaining its link with depression, and whether there is a way to influence those perceptions so that people might experience less negative emotional states (e.g., ensuring people that following the necessary guidelines would most likely prevent infection).

The unique COVID-19 pandemic is characterized by uncertainty regarding the disease, the measures needed to contain it, and when its threat will be eliminated. Uncertainty Management Theory maintains that, in the process of uncertainty management, fairness plays an important role (van den Bos \& Lind, 2002). Consistently, cross-cultural fairness evaluations were more evident for individuals with higher compared to lower uncertainty avoidance (Otto et al., 2011), and for such individuals, a stronger personal belief in a just world helped in sustaining mood under threat (Nudelman et al., 2016). The findings of the current study also support the unique role of justice and fairness perceptions and beliefs in maintaining well-being during times of uncertainty. 


\section{Limitations}

This study included samples from three countries to assess the consistency of its results. Nevertheless, replication studies are necessary in countries with unique characteristics pertinent to this investigation, such as the USA, which demonstrated COVID-19 risk perceptions that differed from other countries (Dryhurst et al., 2020). Moreover, the samples were collected using different methodologies, resulting in greater confidence in the findings from Israel (relatively large and representative sample) compared with those from Germany and India. However, the similar pattern of results across the different sampling techniques and cultures greatly increases the confidence in the research findings.

The cross-sectional nature of the current research impedes the ability to properly assess causality. For example, determining that personal belief in a just world is a precursor of depression might be an oversimplification, since the manifestation of personality traits might change in light of certain situational characteristics, such as justice beliefs leading to higher or lower helping behavior toward victims under different circumstances (Miller, 1977). Correspondingly, initial perceptions of COVID19 might stimulate particular personal belief in a just world mechanisms that shape later perceptions. Consequently, longitudinal and experimental study designs are needed to validate the directionality of the relationships proposed in this manuscript.

Another shortcoming is related to the measures utilized in this study. Although short measures are an acceptable way of assessing personality traits, scales encompassing more items to reach better reliability scores should be used to replicate the current findings. Moreover, COVID-19 perceptions were limited to single items assessing probability, severity, and self-efficacy. Although these are central in fear processes (Ruiter et al., 2014), the effects of personality traits on depression should be examined when controlling for additional factors such as perceived risk for close others (Mertens et al., 2020). Furthermore, it is important to determine which COVID-19-related constructs that are associated with depression, e.g., fears and social isolation (Ahorsu et al., 2020; Santini et al., 2020), explain part of the variance in depression that was originally associated with personality traits. This may imply possible mechanisms through which personality affects depression, such as particular perceptions (Dalal et al., 2015), and thus indicate pathways that might be addressed in order to alleviate depression.

Notably, this research was conducted relatively at the beginning of the COVID19 pandemic, soon after strict lockdowns had ended in the three countries involved. The patterns uncovered in this investigation might change over time, as COVID19 perceptions become more stable, and certainly after a vaccination is developed. Moreover, other personality traits, such as self-esteem (Sowislo \& Orth, 2013), may also play a role in depression during pandemics. Thus, future studies should continue to explore the degree to which personality traits explain changes over time in depression and other negative emotional states. Furthermore, this should be assessed beyond the effects of the demographic and COVID-19-related variables measured in the current research, as well as include additional relevant factors that are associated with depression, such as socioeconomic conditions (Lorant et al, 2003), religiosity (Braam \& Koenig, 2019), and social support (Grey et al., 2020), with the 
latter having critical importance due to the widespread social isolation during the pandemic.

In conclusion, this study found that depression during the COVID-19 pandemic was not only determined by COVID-19-related perceptions, but also by stable personality traits, namely personal belief in a just world, neuroticism and conscientiousness. Moreover, personal belief in a just world explained depression over and above all other variables. This is in line with theory and findings regarding the important role of personal belief in a just world as a buffer against negative emotions, and points to its protective nature also during times of stress and uncertainty.

Funding This research was supported by a grant from the International Society for Justice Research and a grant from the Israel Ministry of Science and Technology.

\section{References}

Ahorsu, D. K., Lin, C. Y., Imani, V., Saffari, M., Griffiths, M. D., \& Pakpour, A. H. (2020). The fear of COVID-19 scale: Development and initial validation. International Journal of Mental Health and Addiction, Advance on. https://doi.org/10.1007/s11469-020-00270-8

American Psychiatric Association. (2013). Diagnostic and statistical manual of mental disorders (5th ed.). . Arlington, VA: Author. https://doi.org/10.1176/appi.books.9780890425596.744053

Bartholomaeus, J., \& Strelan, P. (2019). The adaptive, approach-oriented correlates of belief in a just world for the self: A review of the research. Personality and Individual Differences, 151, 109485. https://doi.org/10.1016/j.paid.2019.06.028

Bogg, T., \& Roberts, B. W. (2004). Conscientiousness and health-related behaviors: A meta-analysis of the leading behavioral contributors to mortality. Psychological Bulletin, 130(6), 887-919. https:// doi.org/10.1037/0033-2909.130.6.887

Braam, A. W., \& Koenig, H. G. (2019). Religion, spirituality and depression in prospective studies: A systematic review. Journal of Affective Disorders, 257, 428-438. https://doi.org/10.1016/j.jad.2019. 06.063

Bücker, S., Nuraydin, S., Simonsmeier, B. A., Schneider, M., \& Luhmann, M. (2018). Subjective wellbeing and academic achievement: A meta-analysis. Journal of Research in Personality, 74, 83-94. https://doi.org/10.1016/j.jrp.2018.02.007

Canet-Juric, L., Andrés, M. L., Del Valle, M., López-Morales, H., Poó, F., Galli, J. I., \& Urquijo, S. (2020). A longitudinal study on the emotional impact cause by the COVID-19 pandemic quarantine on general population. Frontiers in Psychology, 11, 2431. https://doi.org/10.3389/fpsyg.2020. 565688

Centers for Disease Control and Prevention. (2020). Social distancing, quarantine, and isolation. Retrieved August 6, 2020, from https://www.cdc.gov/coronavirus/2019-ncov/prevent-getting-sick/ social-distancing.html

Clark, L. A. (2005). Temperament as a unifying basis for personality and psychopathology. Journal of Abnormal Psychology, 114(4), 505-521. https://doi.org/10.1037/0021-843X.114.4.505

Clark, L. A., \& Watson, D. (1991). Tripartite model of anxiety and depression: Psychometric evidence and taxonomic implications. Journal of Abnormal Psychology, 100(3), 316-336. https://doi.org/10. 1037/0021-843X.100.3.316

Cobb-Clark, D. A., \& Schurer, S. (2012). The stability of big-five personality traits. Economics Letters, 115(1), 11-15. https://doi.org/10.1016/j.econlet.2011.11.015

Correia, I., \& Dalbert, C. (2007). Belief in a just world, justice concerns, and well-being at Portuguese schools. European Journal of Psychology of Education, 22(4), 421-437. https://doi.org/10.1007/ BF03173464 
Cropanzano, R., \& Wright, T. A. (1999). A 5-year study of change in the relationship between well-being and job performance. Consulting Psychology Journal, 51(4), 252-265. https://doi.org/10.1037/ 1061-4087.51.4.252

Dalal, R. S., Meyer, R. D., Bradshaw, R. P., Green, J. P., Kelly, E. D., \& Zhu, M. (2015). Personality strength and situational influences on behavior: A conceptual review and research agenda. Journal of Management, 41(1), 261-287. https://doi.org/10.1177/0149206314557524

Dalbert, C. (1999). The world is more just for me than generally: About the personal belief in a just world scale's validity. Social Justice Research, 12(2), 79-98. https://doi.org/10.1023/A:1022091609047

Dalbert, C. (2001). The justice motive as a personal resource: Dealing with challenges and critical life events. Plenum.

Dalbert, C. (2002). Beliefs in a just world as a buffer against anger. Social Justice Research, 15(2), 123145. https://doi.org/10.1023/A:1019919822628

Donat, M., Peter, F., Dalbert, C., \& Kamble, S. V. (2016). The meaning of students' personal belief in a just world for positive and negative aspects of school-specific well-being. Social Justice Research, 29(1), 73-102. https://doi.org/10.1007/s11211-015-0247-5

Dryhurst, S., Schneider, C. R., Kerr, J., Freeman, A. L. J., Recchia, G., van der Bles, A. M., \& van der Linden, S. (2020). Risk perceptions of COVID-19 around the world. Journal of Risk Research. https://doi.org/10.1080/13669877.2020.1758193

Dudley, N. M., Orvis, K. A., Lebiecki, J. E., \& Cortina, J. M. (2006). A meta-analytic investigation of conscientiousness in the prediction of job performance: Examining the intercorrelations and the incremental validity of narrow traits. Journal of Applied Psychology, 91(1), 40-57. https://doi.org/ 10.1037/0021-9010.91.1.40

Furnham, A. (2003). Belief in a just world: Research progress over the past decade. Personality and Individual Differences, 34(5), 795-817. https://doi.org/10.1016/S0191-8869(02)00072-7

Goldberg, L. R. (1992). The development of markers for the Big-Five factor structure. Psychological Assessment, 4(1), 26-42. https://doi.org/10.1037/1040-3590.4.1.26

Grey, I., Arora, T., Thomas, J., Saneh, A., Tohme, P., \& Abi-Habib, R. (2020). The role of perceived social support on depression and sleep during the COVID-19 pandemic. Psychiatry Research, 293, 113452. https://doi.org/10.1016/j.psychres.2020.113452

Hafer, C. L., Busseri, M. A., Rubel, A. N., Drolet, C. E., \& Cherrington, J. N. (2020). A latent factor approach to belief in a just world and its association with well-being. Social Justice Research, 33(1), 1-17. https://doi.org/10.1007/s11211-019-00342-8

Hofstede, G., Hofstede, G. J., \& Minkov, M. (2010). Cultures and organizations: Software of the mind (3rd ed.). . McGraw-Hill.

Hyland, P., Shevlin, M., McBride, O., Murphy, J., Karatzias, T., Bentall, R. P., Martinez, A., \& Vallières, F. (2020). Anxiety and depression in the Republic of Ireland during the COVID-19 pandemic. Acta Psychiatrica Scandinavica, Advance on. https://doi.org/10.1111/acps.13219

John, O. P., \& Srivastava, S. (1999). The Big Five Trait taxonomy: History, measurement, and theoretical perspectives. In L. A. Pervin \& O. P. John (Eds.), Handbook of personality: Theory and research (Vol. 2, pp. 102-138). Guilford Press.

Kamble, S. V., \& Dalbert, C. (2012). Belief in a just world and wellbeing in Indian schools. International Journal of Psychology, 47(4), 269-278. https://doi.org/10.1080/00207594.2011.626047

Kern, M. L., \& Friedman, H. S. (2008). Do conscientious individuals live longer? A quantitative review. Health Psychology, 27(5), 505-512. https://doi.org/10.1037/0278-6133.27.5.505

Klein, D. N., Kotov, R., \& Bufferd, S. J. (2011). Personality and depression: Explanatory models and review of the evidence. Annual Review of Clinical Psychology, 7, 269-295. https://doi.org/10.1146/ annurev-clinpsy-032210-104540

Koltko-Rivera, M. E. (2004). The psychology of worldviews. Review of General Psychology, 8, 3-58. https://doi.org/10.1037/1089-2680.8.1.3

Kotov, R., Gamez, W., Schmidt, F., \& Watson, D. (2010). Linking "Big" personality traits to anxiety, depressive, and substance use disorders: A meta-analysis. Psychological Bulletin, 136(5), 768-821. https://doi.org/10.1037/a0020327

Krueger, R. F., \& Tackett, J. L. (2003). Personality and psychopathology: Working toward the bigger picture. Journal of Personality Disorders, 17(2), 109-128. https://doi.org/10.1521/pedi.17.2.109.23986

Lerman, S. F., Rudich, Z., Brill, S., Shalev, H., \& Shahar, G. (2015). Longitudinal associations between depression, anxiety, pain, and pain-related disability in chronic pain patients. Psychosomatic Medicine, 77(3), 333-341. https://doi.org/10.1097/PSY.0000000000000158

Lerner, M. J. (1980). The belief in a just world. Springer. https://doi.org/10.1007/978-1-4899-0448-5_2 
Lerner, M. J., \& Miller, D. T. (1978). Just world research and the attribution process: Looking back and ahead. Psychological Bulletin, 85(5), 1030-1051. https://doi.org/10.1037/0033-2909.85.5.1030

Lipkus, I. M., Dalbert, C., \& Siegler, I. C. (1996). The importance of distinguishing the belief in a just world for self versus for others: Implications for psychological well-being. Personality and Social Psychology Bulletin, 22(7), 666-677. https://doi.org/10.1177/0146167296227002

Lorant, V., Deliège, D., Eaton, W., Robert, A., Philippot, P., \& Ansseau, M. (2003). Socioeconomic inequalities in depression: A meta-analysis. American Journal of Epidemiology, 157, 98-112. https:// doi.org/10.1093/aje/kwf182

Lovibond, S. H., \& Lovibond, P. F. (1995). Manual for the depression anxiety stress scales (2nd ed.). . Psychology Foundation. https://doi.org/10.1016/0005-7967(94)00075-U

Maddux, J. E., \& Rogers, R. W. (1983). Protection motivation and self-efficacy: A revised theory of fear appeals and attitude change. Journal of Experimental Social Psychology, 19(5), 469-479. https:// doi.org/10.1016/0022-1031(83)90023-9

Malouff, J. M., Thorsteinsson, E. B., \& Schutte, N. S. (2005). The relationship between the five-factor model of personality and symptoms of clinical disorders: A meta-analysis. Journal of Psychopathology and Behavioral Assessment, 27(2), 101-114. https://doi.org/10.1007/s10862-005-5384-y

Meade, A. W., \& Craig, S. B. (2012). Identifying careless responses in survey data. Psychological Methods, 17(3), 437-455. https://doi.org/10.1037/a0028085

Mertens, G., Gerritsen, L., Duijndam, S., Salemink, E., \& Engelhard, I. M. (2020). Fear of the coronavirus (COVID-19): Predictors in an online study conducted in March 2020. Journal of Anxiety Disorders, 74, 102258. https://doi.org/10.1016/j.janxdis.2020.102258

Miller, D. T. (1977). Altruism and threat to a belief in a just world. Journal of Experimental Social Psychology, 13(2), 113-124. https://doi.org/10.1016/S0022-1031(77)80004-8

Nudelman, G. (2013). The belief in a just world and personality: A meta-analysis. Social Justice Research, 26(2), 105-119. https://doi.org/10.1007/s11211-013-0178-y

Nudelman, G., \& Ivanova, E. (2018). The relationship between frequency of performance and perceived importance of health behaviours. Journal of Health Psychology. https://doi.org/10.1177/13591 05318770724

Nudelman, G., \& Nadler, A. (2017). The effect of apology on forgiveness: Belief in a just world as a moderator. Personality and Individual Differences, 116, 191-200. https://doi.org/10.1016/j.paid.2017. 04.048

Nudelman, G., \& Otto, K. (2021). Personal Belief in a Just World and Conscientiousness: A meta-analysis, facet-level examination, and mediation model. British Journal of Psychology, 112, 92-119. https://doi.org/10.1111/bjop.12438

Nudelman, G., Otto, K., \& Dalbert, C. (2016). Can belief in a just world buffer mood and career prospects of people in need of risk protection? First Experimental Evidence. Risk Analysis, 36(12), 2247-2257. https://doi.org/10.1111/risa.12588

O’Connor, M. C., \& Paunonen, S. V. (2007). Big Five personality predictors of post-secondary academic performance. Personality and Individual Differences, 43(5), 971-990. https://doi.org/10.1016/J. PAID.2007.03.017

OECD. (2013). Trust in government, policy effectiveness and the governance agenda. In Government at a glance 2013. OECD Publishing. https://doi.org/10.1787/gov_glance-2013-6-en.

OECD. (2021). Trust in government (indicator). https://doi.org/10.1787/1de9675e-en. Retrieved March $25,2021$.

Otto, K., Baumert, A., \& Bobocel, D. R. (2011). Cross-cultural preferences for distributive justice principles: Resource type and uncertainty management. Social Justice Research, 24(3), 255-277. https:// doi.org/10.1007/s11211-011-0135-6

Otto, K., Boos, A., Dalbert, C., Schöps, D., \& Hoyer, J. (2006). Posttraumatic symptoms, depression, and anxiety of flood victims: The impact of the belief in a just world. Personality and Individual Differences, 40(5), 1075-1084. https://doi.org/10.1016/j.paid.2005.11.010

Paulus, D. J., Vanwoerden, S., Norton, P. J., \& Sharp, C. (2016). From neuroticism to anxiety: Examining unique contributions of three transdiagnostic vulnerability factors. Personality and Individual Differences, 94, 38-43. https://doi.org/10.1016/j.paid.2016.01.012

Pryce, C. R., Azzinnari, D., Spinelli, S., Seifritz, E., Tegethoff, M., \& Meinlschmidt, G. (2011). Helplessness: A systematic translational review of theory and evidence for its relevance to understanding and treating depression. Pharmacology and Therapeutics, 132(3), 242-267. https://doi.org/10.1016/j. pharmthera.2011.06.006 
Purohit, Y. S., \& Simmers, C. A. (2006). Power distance and uncertainty avoidance: A cross-national examination of their impact on conflict management modes. Journal of International Business Research, 5(1), 1-19.

Rammstedt, B., \& John, O. P. (2007). Measuring personality in one minute or less: A 10-item short version of the Big Five Inventory in English and German. Journal of Research in Personality, 41, $203-$ 212. https://doi.org/10.1016/j.jrp.2006.02.001

Rosenstock, I. M. (1974). Historical origins of the health belief model. Health Education Monographs, 2(4), 328-335. https://doi.org/10.1177/109019817400200403

Ruiter, R. A. C., Kessels, L. T. E., Peters, G.-J.Y., \& Kok, G. (2014). Sixty years of fear appeal research: Current state of the evidence. International Journal of Psychology, 49(2), 63-70. https://doi.org/10. 1002/ijop.12042

Santini, Z. I., Jose, P. E., York Cornwell, E., Koyanagi, A., Nielsen, L., Hinrichsen, C., Meilstrup, C., Madsen, K. R., \& Koushede, V. (2020). Social disconnectedness, perceived isolation, and symptoms of depression and anxiety among older Americans (NSHAP): A longitudinal mediation analysis. The Lancet Public Health, 5(1), e62-e70. https://doi.org/10.1016/S2468-2667(19)30230-0

Schmitt, D. P., Allik, J., McCrae, R. R., \& Benet-Martínez, V. (2007). The geographic distribution of big five personality traits. Journal of Cross-Cultural Psychology, 38(2), 173-212. https://doi.org/10. 1177/0022022106297299

Sowislo, J. F., \& Orth, U. (2013). Does low self-esteem predict depression and anxiety? A meta-analysis of longitudinal studies. Psychological Bulletin, 139(1), 213-240. https://doi.org/10.1037/a0028931

Sutton, R. M., \& Douglas, K. M. (2005). Justice for all, or just for me? More evidence of the importance of the self-other distinction in just-world beliefs. Personality and Individual Differences, 39(3), 637-645. https://doi.org/10.1016/j.paid.2005.02.010

Sutton, R. M., Stoeber, J., \& Kamble, S. V. (2017). Belief in a just world for oneself versus others, social goals, and subjective well-being. Personality and Individual Differences, 113, 115-119. https://doi. org/10.1016/j.paid.2017.03.026

The World Bank. (2020). GNI per capita, Atlas method [data file]. Retrieved from https://datacatalog. worldbank.org/dataset/gni-capita-ranking-atlas-method-and-ppp-based

van den Bos, K., \& Lind, E. A. (2002). Uncertainty management by means of fairness judgments. Advances in Experimental Social Psychology, 34, 1-60. https://doi.org/10.1016/s0065-2601(02) 80003-X

Wagner, J., Lüdtke, O., \& Robitzsch, A. (2019). Does personality become more stable with age? Disentangling state and trait effects for the big five across the life span using local structural equation modeling. Journal of Personality and Social Psychology, 116(4), 666-680. https://doi.org/10.1037/ pspp0000203

Watson, D., Wiese, D., Vaidya, J., Tellegen, A., Watson, D., Tellegen, A., \& David, W. (1999). The two general activation systems of affect: Structural findings, evolutionary considerations, and psychobiological evidence. Journal of Personality and Social Psychology, 76(5), 820-858. https://doi.org/ 10.1037/0022-3514.76.5.820

Witte, K. (1992). Putting the fear back into fear appeals: The extended parallel process model. Communication Monographs, 59(4), 329-349. https://doi.org/10.1080/03637759209376276

World Health Organization. (2020a). Naming the coronavirus disease (COVID-19) and the virus that causes it. Retrieved August 10, 2020, from https://www.who.int/emergencies/ diseases/novel-coron avirus-2019/technical-guidance/naming-the-coron avirus-disea se-(covid-2019)-and-the-virus-that-causes-it

World Health Organization. (2020b). Survey tool and guidance. Retrieved July 25, 2020, from https:// www.euro.who.int/en/health-topics/health-emergencies/coronavirus-covid-19/technical-guida nce/who-tool-for-behavioural-insights-on-covid-19/survey-tool-and-guidance-behavioural-insig hts-on-covid-19,-17-april-2020

World Health Organization. (2021). Coronavirus disease (COVID-19) advice for the public. Retrieved March 25, 2021, from https://www.who.int/emergencies/diseases/novel-coronavirus-2019/ advice-for-public

Publisher's Note Springer Nature remains neutral with regard to jurisdictional claims in published maps and institutional affiliations. 